\title{
Urban health extension program model housing and household visits improved the utilization of health Services in Urban Ethiopia: a community-based cross- sectional study
}

\author{
Nebiyou Tafesse ${ }^{1 *}$, Aregawi Gesessew ${ }^{1}$ and Ergataw Kidane ${ }^{2}$
}

\begin{abstract}
Background: The government of Ethiopia launched an innovative program called Urban Health Extension Program (UHEP) in 2009, aims to produce better health outcomes to the urban populations using urban health extension professionals (UHE-ps) by enabling households to implement most health intervention packages designed by the government, which is referred to as model households (practice and implement at least $75 \%$ of the training provided by UHE-ps on UHEP packages). The objective of this study was to assess health service use and its associated factors.

Methods: A community-based cross-sectional study was conducted to assess the health service use in Addis Ababa. Structured questionnaires were filled out by 1086 women, and a binary logistic regression was performed.

Results: Urban health extension professionals performed home visits to $57.1 \%$ ( $95 \% \mathrm{Cl}$ (confidence interval) $=54.2$ to 59.8\%) of the households. Mothers who had heard of the program (had information about UHEP) were 2.13 times more likely to visit the health center $(\mathrm{HC})$ ( $\mathrm{AOR}$ (adjusted odds ratio) $=2.13,95 \% \mathrm{Cl}=1.36$ to 3.32 ) than mothers who had not heard of the program. Mothers from model households were 2.12 times more likely to visit the HC (AOR $=2.12,95 \% \mathrm{Cl}=1.16$ to 3.88 ) than mothers from non-model households. Mothers whose households were visited by the UHE-ps were 1.89 times more likely to visit the $\mathrm{HC}(\mathrm{AOR}=1.89,95 \% \mathrm{Cl}=1.22$ to 2.94 ) than mothers whose households were not visited. Similarly, mothers who were in the reproductive age group (18 to 49 years) were 1.74 times more likely to visit the $\mathrm{HC}(\mathrm{AOR}=1.74,95 \% \mathrm{Cl}=1.12$ to 2.71$)$ than mothers above 49 years old.

Conclusions: Model households and mothers in the reproductive age group exhibited significant associations with health service use. Sustaining the practices of graduated and certified model households is essential to maximize the benefits of the UHEP's activities regarding health service use. Regular home visits to both model and non-model households are essential to scale up health service use and design re-graduation or other sustainable options for already graduated households.
\end{abstract}

Keywords: UHE-ps, Home visit, Model household, Graduated, Health services, Non-model household

\footnotetext{
* Correspondence: nebiyou.tafesse@aau.edu.et

${ }^{1}$ Menelik II Health Science College, Kotebe Metropolitan University, PO Box:

3268, Addis Ababa, Ethiopia

Full list of author information is available at the end of the article
}

(C) The Author(s). 2019 Open Access This article is distributed under the terms of the Creative Commons Attribution 4.0 International License (http://creativecommons.org/licenses/by/4.0/), which permits unrestricted use, distribution, and reproduction in any medium, provided you give appropriate credit to the original author(s) and the source, provide a link to the Creative Commons license, and indicate if changes were made. The Creative Commons Public Domain Dedication waiver (http://creativecommons.org/publicdomain/zero/1.0/) applies to the data made available in this article, unless otherwise stated. 


\section{Background}

The government of Ethiopia launched an innovative program called Urban Health Extension Program (UHEP) in 2009, intended to produce good health status to the urban populations using urban health extension professionals (UHE-ps)as lead implementer of the program [1]. The purpose of the program is to ensure access and quality of services for the urban community. With 15 UHEP packages, the UHEP was initiated in seven regions of the country (Tigray, Amhara, Oromia, SNNPR (southern nation, nationalities people's region) Harari, DD (Diredawa) and (AA) (Addis Ababa) [2]. The site of work for the (UHE-ps) is in the health centers serving 40, 000 community members.

The ultimate aim of the UHEP is to produce model households. The health service extension program contains 16 rural extension program packages, since there is separate health education and communication package (in contrast to the UHEP packages, of which there are 15 because it is thought that this package can serve as a tool for all the packages of the UHEP (Table 1). Households that attend at least $75 \%$ of the training and put at least $75 \%$ of the UHEP packages into practice will be graduated and certified by the catchment UHE-ps [2].

A number of factors have been identified as the leading causes of poor health service utilization such as

Table 1 The 15 UHEP packages implemented in Addis Ababa, Ethiopia, 2015

\begin{tabular}{|c|c|c|}
\hline s.no & Type of packages & Packages of the UHEP \\
\hline \multirow[t]{3}{*}{1} & \multirow[t]{3}{*}{$\begin{array}{l}\text { Disease prevention } \\
\text { and control }\end{array}$} & $\begin{array}{l}\text { 1. HIV/AIDS and tuberculosis } \\
\text { control }\end{array}$ \\
\hline & & $\begin{array}{l}\text { 2. Malaria prevention and } \\
\text { control }\end{array}$ \\
\hline & & $\begin{array}{l}\text { 3. First aid and emergency } \\
\text { measures }\end{array}$ \\
\hline \multirow[t]{5}{*}{2} & \multirow[t]{5}{*}{ Family health } & 1. Maternal and child health \\
\hline & & 2. Family planning \\
\hline & & 3. Immunization \\
\hline & & 4. Nutrition \\
\hline & & $\begin{array}{l}\text { 5. Adolescent reproductive } \\
\text { health }\end{array}$ \\
\hline \multirow[t]{7}{*}{3} & \multirow{7}{*}{$\begin{array}{l}\text { Hygiene and environmental } \\
\text { sanitation }\end{array}$} & 1. Excreta disposal \\
\hline & & $\begin{array}{l}\text { 2. Solid and liquid waste } \\
\text { disposal }\end{array}$ \\
\hline & & $\begin{array}{l}\text { 3. Water supply and safety } \\
\text { measures }\end{array}$ \\
\hline & & $\begin{array}{l}\text { 4. Food hygiene and safety } \\
\text { measures }\end{array}$ \\
\hline & & 5. Healthy housing \\
\hline & & $\begin{array}{l}\text { 6. Control of insects and } \\
\text { rodents }\end{array}$ \\
\hline & & 7. Personal hygiene \\
\hline
\end{tabular}

inaccessibility of the health care facility, low socioeconomic status, low educational status of the mothers and cultural views and insights of the community. A number of studies showed that these factors categorized as sociodemographic status, autonomy of women's, cultural insights, trends of diseases and health service utilizations, and physical and economic accessibility issues [3-5].

According to Anderson behavioral model risk factors associated to health service utilization can be categorized in to need, enabling and predisposing factors [6]. Health service characteristics can also have impacts on utilization of health services. These characteristics include the health service relevance (tertiary, secondary, or primary care); classification (drugs and medications, hospital, physicians and others); unit of measurements (episode, contact and volume); characteristics of provision, such as the intensity (amount) and time frame (acute or chronic); and frequency of household visits by the health workers [7, 8](Fig. 1).

During the implementation period of the UHEP (particularly between 2012 and 2013 regarding child and maternal health services, an increase was observed for antenatal and postnatal care coverage (from 89.1 to $97.4 \%$ and from 44.5 to $50.5 \%$, respectively) as well as for the percentage of deliveries attended by skilled health personnel (from 20.4 to $23.1 \%$ ), while the percentage of clean and safe deliveries (by health extension workers) declined from 13.2 to $11.6 \%$ in the same period [9]. A report from a miniature demographic release in 2014 showed promising results in Addis Ababa, for example, in terms of utilization of any modern contraceptive method (57\%), antenatal care (94), child mortality (53 per 1000 live births) and the rate of diarrhea in children under five (9.4\%) [10].

This achievement logically links the launch of the UHEP to improvement of the health status of the urban community of Addis Ababa. However, investigation of the determinants and impacts of the program interventions would facilitate further progress toward sustaining development goals. Therefore, the aim of this study was to assess the utilization of the UHEP by the urban community and associated factors.

\section{Methods}

\section{Study design and area}

A community-based cross-sectional study was conducted among women in all 10 sub-cities of Addis Ababa in the month of January 2015 to assess health service utilization due to the UHEP and associated factors.

\section{Study population and sampling}

The study population included women over the age of 18 , since the majority of services provided by the UHEP involve women in reproductive age groups. The other 


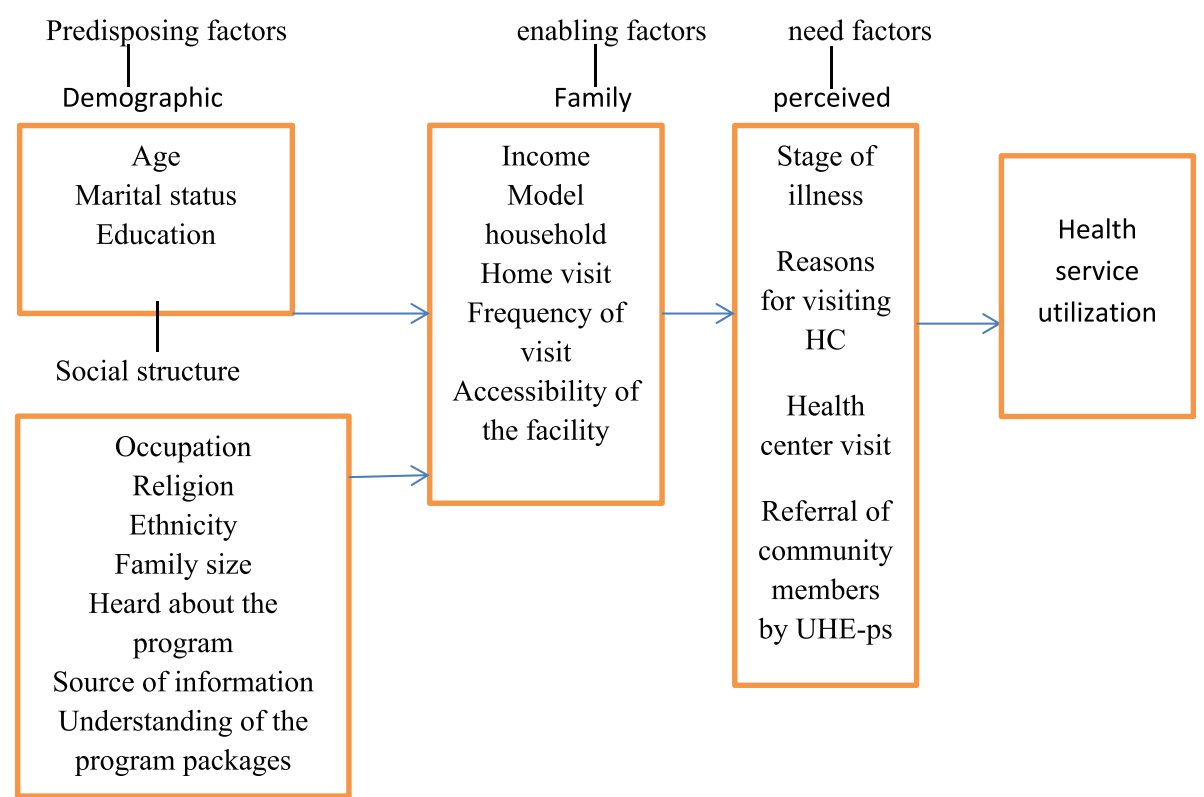

Fig. 1 Anderson behavioral model of health service use

reasons for focusing on women over 18 years old, aside from their position in the reproductive age group, were because they were actively involved in model household training and were more likely than individuals in the non-reproductive age group to finish the training, graduate and become certified [11].

A multistage sampling technique was used to select samples from 10 sub-cities (encompassing a number of woredas) of Addis Ababa. From all woredas (clusters) in each sub-city, a single woreda (cluster) was selected using a simple random sampling technique; from the selected woreda (smallest administrative unit with a population of 40,000), one ketena (the local catchment area within the subunit of the woreda) was selected using a simple random sampling technique; and from the selected ketena, the number of study units was specified based on the population in proportion to the sample size of the total population of the sub-city. The sampling flow was from the sub cities (the largest in terms of population) to the woredas (the components of the sub-city) to the ketena (the components of a woreda).

The unit of study for the quantitative part of this study was the household. To determine the number of households to be included in the study, a single population proportion formula for sample size calculation was used. There were 225,699 (29\%) model households that had been trained and graduated in Addis Ababa out of the total 788,385 eligible households (Addis Ababa City Administration Health Bureau, Annual Performance Report 2014 unpublished). The number of model households is the basic indicator of the program and is used as a single proportion for sample size calculation.

$$
\begin{aligned}
n & \left.=(\mathrm{Z} 1-\alpha / 2)^{2} \mathrm{p}(1-\mathrm{p}) / \mathrm{d}^{2}\right) . \\
n & =(1.96)^{2} \times 0.29 \mathrm{x}\left(1-0.29 / 0.04^{2} .\right. \\
n & =494 \times 2(\text { for the design effect })=988+10 \% \\
\text { non-response rate }=1086 . &
\end{aligned}
$$

\section{Data collection}

A structured questionnaire checklist was prepared based on the consultation of national and regional guidelines as well as previous health service utilization studies conducted in developing countries $[6,12]$. The questionnaire was designed based on enabling, predisposing and need factors from the Anderson behavioral model of health service use. Face-to-face interviews of the female head (age over 18) of the sampled households were conducted using a structured questionnaire.

Twenty data collectors and 10 supervisors were recruited and participated in 5 days of training. The purpose of the training was to familiarize the survey team with the objectives of the study, procedures to be adhered to, and ethical issues. The data collectors were diploma-holding nurses, and the supervisors were BSc (Bachelor of Science) degree-holding nurse professionals and health officers who were familiar with the program.

Pre-testing checklists were applied in a pilot manner to $10 \%$ of the sample prior to the actual fieldwork. The quality of fieldwork during data collection has definite implications for the quality of the end result. Networks of enumerators, supervisors, technical working groups (TWGs), sub-city focal persons, woreda focal persons, local guides and principal investigators designed 
immediate solutions for the challenges faced during data collection. Supervisors were assigned and played roles in checking whether data collectors were collecting data as per the guidelines or not. They also checked the consistency and completeness of the collected quantitative data and submitted the data on the same day.

\section{Operational definitions \\ Model household}

A household that implements $85 \%$ of the 15 different intervention health.

packages.

\section{Non-model household}

A household that implements less than $75 \%$ of the 15 different intervention health packages.

\section{Voluntary community health workers}

Community members who are at the frontline of the implementation of the program and volunteer to support UHE-ps.

\section{Health development team leader}

A community member who is at the frontline of the implementation of the program and implements $75 \%$ of the health packages.

\section{Predisposing factors}

UHEP-related (hearing of and understanding UHEP) and belief-related factors (perception of health services and health professionals) explaining an individual's decision to use health services, any demographic parameter (sex, age, marital status), and social structure (education, occupation, family size, ethnicity, religion).

\section{Enabling factors}

Factors that influence utilization behavior (income, home visits by UHE-ps, frequency of home visits, services provided in the $\mathrm{HC}$ ).

\section{Need factors}

Individuals' perceived need to use heath care services based on their perceived illness and/or clinically evaluated illness (type and stage of illness).

\section{Stable source of income}

As mentioned, a persistent and consistent source of income.

\section{Frequency of home visits by UHE-ps}

The number of UHE-ps visits within 1 week or month, which we categorized as more-frequent visits if there was at least one visit per month and as no visits or less-frequent visits if there was no visit at all or if there was one visit within more than 1 month.

\section{Health center}

A government health facility serving the general public through the city administration of Addis Ababa.

\section{Preference of health center}

A patient's or community member's choice of health facility in the study area.

\section{Health service utilization}

Health center utilization by the community members in the study area.

The conduct of UHE-ps and the quality of services were assessed according to the study participants' perceptions of UHE-p conduct and the services provided in the HC, respectively, using a 5-point Likert scale, ranging from 1 (poor) to 5 (very good). The comprehension/understanding of the UHEP was also assessed according to study participants' perceptions of their UHEP knowledge using "Yes" or "No" responses, and study participants who mentioned the exact number of UHEP packages (i.e., 15 packages) were tagged as having "accurately remembered the number of UHEP packages".

\section{Data analysis}

Quantitative data were cleaned and entered into EPIDATA (created by EpiData Association, 1999, Denmark), and SPSS (Statistical Package for the Social Sciences, version17, SPSS Inc., 2007, Chicago) was used to analyze descriptive and inferential statistics.

\section{Predisposing factor codes and definition}

Age was coded as "0" for the non -reproductive age group (50-98 years) and " 1 " for the reproductive age group (1849 years). Mothers' occupations were coded as " 0 " for government-employed and other jobs " 1 " for housewives. Education was coded as " 0 " for illiterate and " 1 " for at least reading and writing. Hearing about the UHEP was coded as " 0 " for no and " 1 " for yes, and the understanding of the UHEP packages was coded as "0" for no and "1" for yes. Facility preference was coded as follows: $1=$ health center (public), 2 = hospital (public), 3 = private (hospitals /clinics). "The ethno linguistic groups were labeled as follows: $1=$ Amhara, $2=$ Oromo, and $3=$ others; religion was labeled as follows: 1 = Orthodox Christian, 2 = Muslim, 3 = Protestant".

\section{Enabling factors codes and definition}

Model households were coded as " 0 " for no and " 1 " for yes. Home visits by UHE-ps were coded as " 0 " for no and " 1 " for yes, and the frequency of visits was coded as " 0 " for no visits (less-frequent visits) and " 1 " for frequent visits by UHE-ps (at least one visits every 4 weeks). 


\section{Need factors codes and definitions}

Consultation of the UHE-ps in case of sickness was labeled as $1=$ yes, and $2=$ no. Reasons for visiting a health facility were labeled as follows: $1=$ child illness, $2=$ family planning, $3=$ ANC, $4=$ delivery, $5=$ postnatal, $6=$ family illness or $7=$ immunization. The response to the question "At what stage of the illness do you visit the health facility?" was labeled as follows: 1 = soon after the illness starts, 2 = if there is no improvement, $3=$ if the sick person is unable to eat $/$ drink, or $4=$ other.

Binary logistic regression was used to identify the predictors of $\mathrm{HC}$ visits by the community. Due to the multistage sampling procedure, individual women were nested within sub-cities; hence, the likelihood of women seeking $\mathrm{HC}$ visits was likely to correlate with sub-city residents. For the dependent variable of $\mathrm{HC}$ visits, two models were estimated: an intercept-only model, an empty model that contained no covariates, and a full model that included both individual variables and sub-cities. The intercept-only model allowed us to evaluate the extent of cluster variation in relation to the utilization of the UHEP.

Both the crude odds ratio (COR) and the adjusted odds ratio (AOR) were used for reporting the results of the binary logistic regression. The estimation of population parameters was presented with a $95 \%$ confidence interval (CI). To report statistical significance, a $P$ value of 0.05 was taken as the cut-off point.

\section{Results}

A total of 1086 households were sampled in the survey, and 1078 females participated in this study, corresponding to a response rate of $99.1 \%$. Additionally, 954 of the study participants visited the health center during the year $(89.1,95 \% \mathrm{CI}=87.1,90.9)$.

\section{Predisposing factors}

The age of the respondents ranged from 18 to 98 years with a mean age of $39.14 \pm 11.98$ years. Most of the study participants $(67.3,95 \% \mathrm{CI}=64.5$ to $70.2 \%)$ were married, (19.8, $95 \% \mathrm{CI}=17.5$ to $22.2 \%)$ were illiterate, $(64.3,95 \%$ $\mathrm{CI}=61.4$ to $66.9 \%)$ and/or were housewives. Regarding religion and ethnicity, participants were mainly Orthodox Christian (77.3, 95\% CI $=74.9$ to 79.8), Amhara (44.7, $95 \% \mathrm{CI}=41.8$ to $47.8 \%)$ and $/$ or Oromo $(24.4,95 \% \mathrm{CI}=22.0$ to $27 \%)$. The mean family size was $4.5 \pm 2.25$ individuals. Approximately $57.1 \%(95 \% \mathrm{CI}=54.0$ to 60.0$)$ of the participants had a sustainable source of income (Table 2).

The majority $(909 ; 84.4,95 \% \mathrm{CI}=82.2$ to $86.4 \%)$ of the study participants had heard about the UHEP, and the UHE-ps were the source of this information for 699 (76.9, 95\% CI $=74.0-79.6 \%)$ of them. Out of the 1078 study participants, 571 felt that they understood/comprehended what the UHEP was.
Table 2 Socio-demographic characteristics of the study participants in Addis Ababa, Ethiopia, 2015 ( $n=1078)$

\begin{tabular}{|c|c|c|}
\hline & Number (N) & $\begin{array}{l}\text { Percent (\%) } \\
(95 \% \mathrm{Cl})\end{array}$ \\
\hline \multicolumn{3}{|l|}{ Variables } \\
\hline \multicolumn{3}{|l|}{ Age group } \\
\hline $18-49$ & 861 & $80(77.8,82.4)$ \\
\hline $50-98$ & 215 & $20(17.6,22.2)$ \\
\hline Total & 1076 & \\
\hline \multicolumn{3}{|l|}{ Occupation } \\
\hline Housewife & 693 & $64.3(61.4-66.9)$ \\
\hline Government employed and other jobs & 384 & $35.7(33.1-38.6)$ \\
\hline Total & 1077 & 100 \\
\hline \multicolumn{3}{|l|}{ Steady source of income } \\
\hline Yes & 611 & $57.1(54.1,59.8)$ \\
\hline No & 459 & $42.9(40.2,45.9)$ \\
\hline Marital status & 1070 & 100 \\
\hline Married & 723 & $67.3(64.5,70.2)$ \\
\hline Single, separated, widow or divorced & 351 & $32.7(29.8,35.5)$ \\
\hline Total & 1074 & 100 \\
\hline Total & 1070 & 100 \\
\hline \multicolumn{3}{|l|}{ Number of family members } \\
\hline $2-6$ & 853 & $84(81.9-86.3)$ \\
\hline $7-11$ & 156 & $15.4(13.1-17.4)$ \\
\hline $12-16$ & 7 & $0.7(0.2-1.1)$ \\
\hline Total & 1016 & 100 \\
\hline \multicolumn{3}{|l|}{ Under-five children } \\
\hline Have under-five children & 707 & $65.6(62.8-68.3)$ \\
\hline Do not have under-five children & 370 & $34.4(31.7-37.2)$ \\
\hline Total & 1077 & 100 \\
\hline \multicolumn{3}{|l|}{ Religion } \\
\hline Orthodox Christian & 823 & $77.3(74.9-79.8)$ \\
\hline Muslim & 162 & $15(12.8-17.0)$ \\
\hline Protestant & 79 & $7.3(5.8-9.1)$ \\
\hline Total & 1077 & 100 \\
\hline \multicolumn{3}{|l|}{ Educational status } \\
\hline Illiterate & 213 & $19.8(17.5-22.2)$ \\
\hline At least read and write & 863 & $80.2(77.8-82.5)$ \\
\hline Total & 1076 & 100 \\
\hline
\end{tabular}

Comparatively, the most frequently recalled packages were solid and liquid waste management, latrine construction and utilization, personal and environmental hygiene, and healthy housing, which were mentioned by $76.3,74.2,68.2$, and $51.5 \%$ of study participants, respectively. The moderately recalled packages were tuberculosis, leprosy and HIV control, water supply and food hygiene, family planning, non-communicable diseases, 
and immunization, which were mentioned by $44.7,36.7$, 36,29 , and $24.2 \%$ of study participants, respectively. The least recalled packages were adolescent and reproductive health, health education, nutrition, first aid and accident prevention, which were mentioned by 17.9, 16.9, 15.5, 7.3 and $5.1 \%$ of the participants, respectively (Table 2 ). The conduct of the UHE-ps was rated as "good" by 93.0\% (95\% CI $=90.7$ to $95.0 \%)$ of the participants. Similarly, the services provided in the HCs were viewed as being of "good quality" by $77.0 \%$ of participants ( $95 \%$ CI $=74.3$ to 79.7 ) (Table 3$)$.

\section{Enabling factors}

Three hundred eighteen $(29.6,95 \% \mathrm{CI}=26.9$ to 32.3$)$ households were model households; 614 study participants $(57.1,95 \% \mathrm{CI}=54.2$ to $59.8 \%)$ received home visits by UHE-ps; and $391(64.5,95 \% \mathrm{CI}=60.4$ to $68.3 \%)$ received frequent visits (at least one visits every 4 weeks). Most of the study participants $(91.8,95 \% \mathrm{CI}=90.0$ to 93.6\%) travelled on foot to visit the health centers (Table 4).

\section{Need factors}

The main reasons for visiting HCs were family illness, child illness and family planning, at $48.7 \%(95 \% \mathrm{CI}=41.3$ to 56.1$), 19.6 \%(95 \% \mathrm{CI}=14.3$ to $25.4 \%)$ and $14.3 \%$ $(95 \% \mathrm{CI}=9.5$ to $19.6 \%)$, respectively. In cases of illness, $65.0 \%$ (95\% CI $=62.0$ to $67.8 \%$ ) of the study participants visited the $\mathrm{HC}$ soon after the illness began, and 32.5\% $(95 \% \mathrm{CI}=29.7$ to $35.4 \%)$ visited only if there was no improvement (Table 5).

\section{Association of Health Center Visits with household sociodemographic and health characteristics}

The bivariate logistic regression showed that $(\mathrm{HC})$ visits exhibited significant associations with mothers' family incomes, hearing (having information) about the UHEP, model household status, households having under-five children, home visits made by UHE-ps and age categories. However, $\mathrm{HC}$ visits exhibited no significant association with mothers' occupations, the frequency of visits, the understanding of the UHEP packages, the quality of health centers, or referral of community members by UHE-ps.

Mothers having a stable source of income were 0.63 times less likely to visit the $\mathrm{HC}(\mathrm{AOR}=0.63,95 \% \mathrm{CI}=0.42$ to 0.88 ) than mothers with no sustainable source of income. Mothers who had heard of or had information about the UHEP were 2.13 times more likely to visit the $\mathrm{HC}(\mathrm{AOR}=2.13,95 \% \mathrm{CI}=1.36$ to 3.32$)$ than mothers who had not heard of the program. Mothers from model households were 2.12 times more likely to visit the $\mathrm{HC}$ $(\mathrm{AOR}=2.12,95 \% \mathrm{CI}=1.16$ to 3.88$)$ than mothers from non-model households. Mothers whose households were
Table 3 Knowledge and preferences of study participants regarding the Urban Health Extension Program in Addis Ababa, Ethiopia, 2015

\begin{tabular}{|c|c|c|}
\hline Variables & Number (N) & Percent $(\%)(95 \% \mathrm{Cl})$ \\
\hline \multicolumn{3}{|c|}{ Community perception of health facility quality } \\
\hline Good & 740 & $77.0(74.3-79.7)$ \\
\hline Bad & 221 & $23.0(20.3-25.7)$ \\
\hline Total & 961 & 100 \\
\hline \multicolumn{3}{|c|}{ Community perception of the conduct of UHE-ps } \\
\hline Good & 541 & $93.0(90.7-95.0)$ \\
\hline Bad & 41 & $7.0(5.0-9.3)$ \\
\hline Total & 582 & \\
\hline \multicolumn{3}{|l|}{ Heard about UHEP } \\
\hline Yes & 909 & $84.4(82-86.7)$ \\
\hline No & 168 & $15.6(13.3-18.0)$ \\
\hline Total & 1077 & 100 \\
\hline \multicolumn{3}{|l|}{ Source of information } \\
\hline UHE-ps & 699 & $76.9(74.0-79.6)$ \\
\hline Other health professionals & 43 & $4.7(3.3-6.2)$ \\
\hline Community members & 77 & $8.5(6.7-10.5)$ \\
\hline Mass media & 252 & $27.8(24.9-30.8)$ \\
\hline Total & 1021 & 100 \\
\hline \multicolumn{3}{|l|}{ Understanding UHEP packages } \\
\hline Yes & 909 & $84.4(82.3-86.6)$ \\
\hline No & 168 & $15.6(13.4-17.7)$ \\
\hline Total & 1077 & \\
\hline \multicolumn{3}{|l|}{ Facility preference } \\
\hline Health Center & 880 & $81.8(79.5-84.0)$ \\
\hline Public hospital & 34 & $3.2(2.1-4.3)$ \\
\hline Private hospital & 158 & $14.7(12.5-16.8)$ \\
\hline Total & 1072 & \\
\hline \multicolumn{3}{|l|}{ Which UHEP packages do you know of? } \\
\hline Solid and liquid waste management & 447 & $76.3(72.9-79.7)$ \\
\hline Latrine construction and utilization & 435 & $74.2(70.6-77.8)$ \\
\hline Personal and environmental hygiene & 399 & $68.1(64.5-72.4)$ \\
\hline Healthy housing & 302 & $51.5(47.4-55.5)$ \\
\hline Tuberculosis, leprosy and HIV & 260 & $44.7(40.1-48.8)$ \\
\hline Water supply and food hygiene & 215 & $36.7(32.9-40.4)$ \\
\hline Family planning & 211 & $36(32.1-40.1)$ \\
\hline Non-communicable diseases & 170 & $29.0(25.3-32.6)$ \\
\hline Immunization & 142 & $24.2(20.8-27.8)$ \\
\hline Adolescent and reproductive health & 105 & $17.9(14.8-21.2)$ \\
\hline Health education & 99 & $16.9(13.8-20.0$ \\
\hline Nutrition & 91 & $15.5(12.6-18.8)$ \\
\hline First aid and accidental prevention & 43 & $7.3(5.3-9.6)$ \\
\hline Malaria prevention and control & 30 & $5.1(3.4-7.0)$ \\
\hline Total & 1078 & 100 \\
\hline
\end{tabular}


Table 4 Study participants' income, social status, and Urban Health Extension Program-related status in Addis Ababa, Ethiopia, 2015

\begin{tabular}{|c|c|c|}
\hline Variables & Number(N) & $\begin{array}{l}\text { Percent (\%) } \\
(95 \% \mathrm{Cl})\end{array}$ \\
\hline \multicolumn{3}{|l|}{ Model household } \\
\hline Yes & 318 & $29.6(26.9-32.3)$ \\
\hline No & 758 & $70.4(67.7-73.1)$ \\
\hline Total & 1076 & 100 \\
\hline \multicolumn{3}{|l|}{ Sustainable source of income } \\
\hline Yes & 611 & $57.1(54.0-60.0)$ \\
\hline No & 459 & $42.9(40.0-46.0)$ \\
\hline Total & 1070 & 100 \\
\hline \multicolumn{3}{|l|}{ Home visits by UHE-ps } \\
\hline Yes & 614 & $57.1(54.2-59.8)$ \\
\hline No & 461 & $42.9(40.2-45.8)$ \\
\hline Total & 1075 & 100 \\
\hline \multicolumn{3}{|l|}{ Frequency of home visits by UHE-ps } \\
\hline $\begin{array}{l}\text { Frequent visits by UHE-ps } \\
\text { (at least one visits every } 4 \text { weeks) }\end{array}$ & 391 & $64.5(60.4-68.3)$ \\
\hline No visits (less frequent) & 215 & $35.5(31.7-39.6)$ \\
\hline Total & 606 & \\
\hline \multicolumn{3}{|c|}{ Means of transport to the health facility } \\
\hline Own car & 7 & $0.7(0.2-1.2)$ \\
\hline Public Transport & 72 & $7.4(5.8-9.1)$ \\
\hline On foot & 889 & $91.8(90.0-93.6)$ \\
\hline \multicolumn{3}{|c|}{ What UHE-ps do when they visit the home } \\
\hline Teach us & 482 & $78.1(74.9-81.4)$ \\
\hline Demonstrate to us & 135 & $21.9(18.6-25.1)$ \\
\hline Total & 617 & 100 \\
\hline
\end{tabular}

visited by UHE-ps were 1.89 more likely to visit the $\mathrm{HC}$ ( $\mathrm{AOR}=1.89,95 \% \mathrm{CI}=1.22$ to 2.94$)$ than mothers whose households were not visited. Mothers who had under-five children were 1.96 times more likely to visit the HC (AOR $=1.96,95 \% \mathrm{CI}=1.23$ to 3.12$)$ than mothers who did not have under-five children. Similarly, mothers who were in the reproductive age group (18 to 49 years) were 1.74 times more likely to visit the $\mathrm{HC}(\mathrm{AOR}=1.74,95 \% \mathrm{CI}=1.12$ to 2.71) than mothers older than 49 years. (Table 6).

\section{Discussion}

The results of showed being a model household, hearing (having information) about the UHEP, receiving home visits from UHE-ps, having under-five children, being a mother in the reproductive age group and having a sustainable source of income were independent determinants of $\mathrm{HC}$ utilization. However, $\mathrm{HC}$ visits exhibited no significant association with mothers' occupations, the frequency of visits, understanding the UHEP packages,
Table 5 Reasons and stage of illness for seeking health facility visits and consultation with UHE-ps in Addis Ababa, Ethiopia, 2015

\begin{tabular}{lll}
\hline $\begin{array}{l}\text { Variables } \\
\text { Consultation of UHE-ps in case of sickness }\end{array}$ & $\begin{array}{l}\text { Percent (\%) (95\% } \\
\text { Cl) }\end{array}$ \\
Yes & 196 & $18.2(16.1-20.5)$ \\
No & 880 & $81.8(79.5-83.9)$ \\
Total & 1076 & 100 \\
Reasons for visiting health facility & & \\
Child illness & 37 & $19.6(14.3-25.4)$ \\
Family planning & 27 & $14.3(9.5-19.6)$ \\
ANC & 6 & $3.2(1.1-5.8)$ \\
Delivery & 8 & $4.2(1.6-7.4)$ \\
Postnatal & 2 & $1.1(0-2.6)$ \\
Family illness & 92 & $48.7(41.3-56.1$ \\
Immunization & 4 & $2.1(0.5-4.2)$ \\
Total & 189 & \\
At what stage of the illness do you visit the health facility? \\
Soon after the illness starts & 698 & $65.0(62.0-67.8)$ \\
No improvement of the illness & 349 & $32.5(29.7-35.4)$ \\
If the sick person is unable to eat/ & 21 & $2.0(1.1-2.8)$ \\
drink & & \\
Others & 6 & $0.6(0.2-1.0)$ \\
\hline
\end{tabular}

the quality of the health centers, or referrals of community members by UHE-ps.

Receiving household visits by UHE-ps and being model households exhibited significant associations with $\mathrm{HC}$ visits made by members of the community. The results of this study is in line with a study conducted in Ethiopia indicating that HEW (health extension worker) home visits and after becoming model households exhibited significant positive associations with health service utilization [13]. Other related study showed the potential of preventive home visits for reducing the disability burden, despite the fact that this depends on a number of risk factors and health facility infrastructure [14]. Another systematic review suggested that home visits can reduce chronic cares and mortality [15]. In contrast, a study by Van Haastregt and Diederiks (2000) showed that there was no any studies indicating the effectiveness of household visiting [16]. Another related study suggested that instant community involvements would have maximum benefit [17]. Nevertheless, some systematic reviews of home visiting programs have showed differences related to outcomes associated with the average intensities and durations of the programs $[17,18]$.

This study explored the hypothesis that model households increase the potential to utilize health centers. 
Table 6 Factors associated with utilization of health services by households, Addis Ababa, Ethiopia, 2015 ( $n=1078)$

\begin{tabular}{|c|c|c|c|c|}
\hline \multirow[t]{2}{*}{ Variables } & \multicolumn{2}{|c|}{ Utilization (Health Center visits) = D } & \multirow{2}{*}{$\begin{array}{l}\text { Crude OR } \\
(95 \% \mathrm{Cl})\end{array}$} & \multirow{2}{*}{$\begin{array}{l}\text { Adjusted OR } \\
(95 \% \mathrm{Cl})\end{array}$} \\
\hline & Yes & No & & \\
\hline \multicolumn{5}{|l|}{ Heard about UHEP } \\
\hline Yes & 820 & 83 & $2.57(1.62,3.89)$ & $2.13(1.36,3.32) * *$ \\
\hline No & 134 & 34 & 1.00 & 1.00 \\
\hline \multicolumn{5}{|l|}{ Home visit by UHE-ps } \\
\hline Yes & 569 & 42 & $2.61(1.75,3.89)$ & $1.89(1.22,2.94) * *$ \\
\hline No & 38 & 74 & 1.0 & 1.0 \\
\hline \multicolumn{5}{|l|}{ Sustainable source of income } \\
\hline Yes & 527 & 79 & $0.59(0.38,0.88)$ & $0.63(0.42,0.88) * *$ \\
\hline No & 427 & 37 & 1.0 & 1.0 \\
\hline \multicolumn{5}{|l|}{ Occupation } \\
\hline Housewife & 625 & 65 & $1.52(1.03,2.24)$ & $1.20(0.76,1.88)$ \\
\hline Govt employed and other jobs & 325 & 52 & 1.0 & 1.0 \\
\hline \multicolumn{5}{|l|}{ Model household } \\
\hline Yes & 299 & 17 & $2.69(1.58,4.58)$ & $2.12(1.16,3.88) * *$ \\
\hline No & 654 & 100 & 1.0 & 1.0 \\
\hline \multicolumn{5}{|l|}{ Frequency of visit } \\
\hline Frequent visits by UHE-ps (at least one visit every 4 weeks) & 368 & 22 & $1.73(0.92,3.26)$ & $1.57(0.82,3.02)$ \\
\hline No visit (less frequent) & 193 & 20 & 1.00 & 1.00 \\
\hline \multicolumn{5}{|l|}{ Households with under-five children } \\
\hline Yes & 611 & 313 & $2.07(1.30,3.28)$ & $1.95(1.23,3.12) * *$ \\
\hline No & 92 & 25 & 1.00 & 1.00 \\
\hline \multicolumn{5}{|l|}{ Referral of community members by UHE-ps } \\
\hline Yes & 88 & 865 & $3.87(0.52,28.49)$ & $3.44(0.456,25.87)$ \\
\hline No & 1 & 38 & 1.0 & 1.0 \\
\hline \multicolumn{5}{|l|}{ Age category } \\
\hline $18-49$ & 772 & 84 & $1.68(1.09,2.59)$ & $1.74(1.12,2.71)^{* *}$ \\
\hline $50-98$ & 181 & 33 & 1.0 & 1.0 \\
\hline \multicolumn{5}{|l|}{ Understanding the UHEP packages } \\
\hline Yes & 524 & 45 & $1.57(0.99,2.48)$ & $1.81(0.71,4.65)$ \\
\hline No & 275 & 32 & 1.00 & 1.00 \\
\hline \multicolumn{5}{|l|}{ Community perception on $\mathrm{HC}$ quality } \\
\hline Good & 707 & 7 & $1.56(1.17,2.08)$ & $1.71(1.19,2.47) * *$ \\
\hline Bad & 245 & 6 & 1.00 & 1.00 \\
\hline \multicolumn{5}{|l|}{ Conduct of UHE-ps } \\
\hline Good & 499 & 40 & $17.69(8.49,36.85)$ & $20.39(9.52,43.69)^{* *}$ \\
\hline Bad & 35 & 6 & 1.00 & 1.00 \\
\hline
\end{tabular}

$D$ Dependent variable

This hypothesis is in line with a related findings in Ethiopia showing that women who are model families of an HEP (health extension program) are more likely to exhibit good utilization of maternal health services [19].

Solid and liquid waste management, latrine construction and utilization, personal and environmental hygiene and healthy housing were the packages that were most frequently recalled. The moderately recalled packages included tuberculosis, leprosy and HIV control, water supply and food hygiene, family planning, non-communicable diseases and immunization. The least recalled packages were adolescent and reproductive health, health education, nutrition, first aid and accident prevention. 
The packages that were least or moderately recalled could be due to the focus of UHE-ps on household-level services (even though the program implementation centers also include school and youth centers [1]), since most of the least-recalled packages were to be implemented among youths and adolescents. One exception to this trend was the malaria package, since the study area is not endemic for malaria.

In this study, mothers with a stable source of income were less likely to visit private or highly advanced centers (expensive centers) than mothers with no stable source of income. This discrepancy might have occurred because those mothers who had stable sources of income (affluent) were more likely to visit a government health facility (relatively cheaper centers), similar to mothers with no stable source of income, possibly due to the global and the local economic crisis in Addis Ababa, Ethiopia. This inference is consistent with a study from the USA indicating that hospitalization rates are higher in limited-resource areas than in higher-income areas, where appropriate outpatient care is more readily available [20]. However, this possibility is not consistent with studies from Uganda and Bangladesh that have reported income as one of the most important factors in overcoming barriers to the utilization of health services $[8,12,21]$.

Mothers in the reproductive age group as well as mothers having children under five were more likely to visit the $\mathrm{HC}$, possibly because most of the packages of the UHEP are related to this group of mothers and children under five. This study showed that $\mathrm{HC}$ visits exhibited no significant association with mothers' occupations, the frequency of visits, the understanding of UHEP packages, the quality of health centers and referrals of community members by UHE-ps.

The findings of this study indicated that mothers' occupations exhibited no significant association with $\mathrm{HC}$ visits, which is consistent with another related study conducted in Ethiopia showing that a mother's occupation is not a predictor of health service utilization within the community of West Gojam, Ethiopia [13]. Similarly, a study performed in South Asia and sub-Saharan Africa indicated that the likelihood of using health care for maternal services are similar for both working and non-working women in Tanzania, Bangladesh, India and Pakistan [22]. Similarly, other related study in South Korean showed there is no differences in mortality rates due to occupational differences (between manual versus non-manual labour) [23].

However, studies conducted in Nepal indicated that women who are not working are more likely to utilize health services than working women, which is justified, since most women in Nepal work for family responsibility in the agriculture [24, 25]. A study from Iran also showed that housewives are more likely to utilize health services than other working women [26].

In the present study, numbers of household visits by UHE- ps displayed no significant association with $\mathrm{HC}$ visits. Contrary to this finding, a study from Nepal demonstrated that health worker visits showed as significant association with the health service use [27]. Awareness on the elements of the UHEP in this study is not predictor for the health service use. Another study from Ethiopia showed contrary findings, suggesting that awareness of the components of the packages was positively associated with the health service use [13]. Other similarly contrary findings from greater Lansing showed a statistically significant association between knowledge and level of literacy associated with the health service utilization [28]. However, results from a similar study in Atlanta indicated no association between the literacy level and health service uses [29].

Community perception toward the conduct of UHE-ps and services quality provided in the $\mathrm{HC}$ showed significant association with $\mathrm{HC}$ visits, which might be due to the expansion of health centers in the catchment areas of the urban community. However, contrary results from Ethiopia indicated that community attitudes towards ethical practices of the HEWs and services quality provided in the health facility displayed no significant association with health service utilization [13]. Opposing results from Uganda revealed that the community perceived governmental health facilities substandard cares [30]. Referral of community members by UHE-ps was not found to be a significant predictor of $\mathrm{HC}$ visits in the present study, most likely due to the attitude of the community and UHE-ps themselves, as the UHE-ps were entirely responsible for handling cases at the household level.

According to the Anderson behavioral model initially designed in this study based on predisposing factors (age, hearing about the UHEP, understanding the UHEP (comprehending what the UHEP was)) and enabling factors (model households, home visits by UHE-ps), these factors show significant associations with health service use, which implies that predisposing and enabling factors are well illustrated by this model. However, need factors were not well represented in the model.

\section{Limitations of the study}

The UHEP related variable like home visit made by UHE-ps is the potential predictor in this study however similar related variable called frequency of visit by UHE-ps is not predictor variable for the health service utilization. Similarly hearing about UHEP (having information about the UHEP) is potential predictor, unfortunately understanding of the UHEP packages variable is not predictor for the health service utilization. This 
UHEP related variables expected to show causal ordering (but there is no casual ordering) so this needs further investigation.

The unique characteristics of this study included the use of a large sample size and a high response rate. Nevertheless, the two remaining limitations of this study were recall bias, the study participants might not have remembered all the UHEP services and associated factors, and a lack of baseline data with which to compare the findings of this study.

\section{Conclusions}

The determinants of UHEP factors, such as being model households and receiving home visits from UHE-ps, exhibited significant positive associations with the health services program. Having a sustainable source of income also displayed a significant positive association with health service utilization. Sustaining practices of graduated and certified model households are essential to maximize the benefits of the UHEP activities for health service utilization. Home visits to both model and non-model households on a regular basis are essential to advance health service utilization, in addition to designing re-graduation or other sustainability options for those in graduated model households.

The UHE-ps have diplomas in clinical nursing and work in promotive and preventive aspects of the UHEP. The professionals' career structures in their own field have not yet been established, which makes them unmotivated to continue as UHE-ps. Instead, most of them teach in private colleges with the aim of changing their profession. Designing UHEP-based undergraduate and higher educational training is of paramount importance to utilize the benefits of an innovative UHEP through minimizing the turnover of UHE-ps.

\section{Abbreviations \\ AA: Addis Ababa; AOR: Adjusted Odds Ratio; Cl: Confidence Interval; COR: Crude Odds Ratio; DD: Dire Dawa; HC: Health Center; HDA: Health Development Army; HIV: Human Immunodeficiency Virus; HSU: Health Service Utilization; MH: Model Household; NMH: Non-Model Household; PMTCT: Prevention of Mother to Child Transmission; RRTEC: Research Review Technical Ethical Committee; SNNPR: Southern Nation, Nationalities, Peoples Region; SPSS: Statistical Package for Social Science; UHEP: Urban Health Extension Program; UHE-ps: Urban Health Extension professionals}

\section{Acknowledgments \\ Menelik II Health Science College is duly acknowledged for facilitating an enabling atmosphere for the researchers for the successful accomplishment of this study. Furthermore, we are very grateful to the City government of Addis Ababa Health Bureau for financial support. \\ Funding \\ The funders had no role in study design, data collection and analysis, decision to publish, or preparation of the manuscript.}

\section{Availability of data and materials}

The datasets generated and/or analyzed during the current study are not publicly available because the datasets might be used for other reasons by the funding organization, but they are available from the corresponding author upon reasonable request.

\section{Declarations}

The authors of this study declare that this study is our original work and that all sources of material used for the study have been duly acknowledged.

\section{Authors' contributions}

NT was responsible for generating the concept of this research, the literature review and organization, preparation of the draft research proposal document, organization of the data collection process, data analysis, preparation of the draft data analysis and interpretation, and preparation of the scientific paper or manuscript; he is the corresponding author of the manuscript.

AG participated in the preparation process for the research topic, the research proposal design process, organization of the data collection process, data analysis, preparation of the draft data analysis and interpretation.

EK participated in the research proposal design process, data analysis, and presentation and interpretation of the results. All the authors read and approved the draft manuscript.

\section{Ethics approval and consent to participate}

The study was approved by the Research Review Technical Ethical Committee of Menelik II Health Science College (RRTEC). Meanwhile the technical ethics committee approved the procedure for verbal consent and during this study written consent was not necessary because most of the women are not capable in reading and writing. All the respondents verbal consent response kept in the individual interview questioner in the beginning page and the data collector approved (through signature) for taking verbal consent for the study. Informed verbal consent was requested for each of the respondents, and the right to refuse to respond to any of the questions or refusal of participation was respected. The health managers and coordinators received a letter from the Addis Ababa City Administration Health Bureau requesting cooperative participation with some of the relevant subordinates under the offices and the community.

\section{Consent for publication \\ Not Applicable.}

\section{Competing interests}

The authors of this study declare that there are no competing interests among the authors of this study.

\section{Publisher's Note}

Springer Nature remains neutral with regard to jurisdictional claims in published maps and institutional affiliations.

\section{Author details}

${ }^{1}$ Menelik II Health Science College, Kotebe Metropolitan University, PO Box: 3268, Addis Ababa, Ethiopia. ${ }^{2}$ Yekatit 12 Hospital Medical College, Addis Ababa Health Bureau, Addis Ababa, Ethiopia.

Received: 1 March 2018 Accepted: 4 January 2019

Published online: 14 January 2019

\section{References}

1. John Snow I. Urban health update 2015

2. Banteyerga $\mathrm{H}$. Ethiopia's health extension program: improving health through community involvement. MEDICC Rev. 2011;13(3):46-9.

3. Katung P. Socio-economic factors responsible for poor utilisation of the primary health care services in a rural community in Nigeria. Niger J Med. 2000;10(1):28-9.

4. Navaneetham K, Dharmalingam A. Utilization of maternal health care services in southern India. Soc Sci Med. 2002;55(10):1849-69.

5. Fatmi Z, Avan B. Demographic, socio-economic and environmental determinants of utilisation of antenatal care in a rural setting of Sindh Pakistan. J Pak Med Assoc. 2002;52(4):138-42.

6. Andersen RM. Revisiting the behavioral model and access to medical care: does it matter? J Health Soc Behav. 1995;(1):10.

7. Andersen R, Newman JF. Societal and individual determinants of medical care utilization in the United States. Milbank Mem Fund Q Health Soc. 1973 : 95-124. 
8. Nievar MA, Van Egeren LA, Pollard S. A meta-analysis of home visiting programs: moderators of improvements in maternal behavior. Infant Ment Health J. 2010;31(5):499-520.

9. Health FDRoEMo. Policy and practice information for action 2014.

10. Ethiopia Mini Demographic and Health Survey. 2014.

11. Bureau AACAH. Annual performance report; 2010.

12. Fantahun M, Degu G. Health service utilization in Amhara region of Ethiopia. Ethiop J Health Dev. 2003;17(2):140-7.

13. Yitayal M, Berhane Y, Worku A, Kebede Y. Health extension program factors, frequency of household visits and being model households, improved utilization of basic health services in Ethiopia. BMC Health Serv Res. 2014; 14(1):1.

14. Huss A, Stuck AE, Rubenstein LZ, Egger M, Clough-Gorr KM

Multidimensional preventive home visit programs for community-dwelling older adults: a systematic review and meta-analysis of randomized controlled trials. J Gerontol A Biol Sci Med Sci. 2008;63(3):298-307.

15. Elkan $R$, Egger $M$, Kendrick D, Dewey $M$, Hewitt M, Robinson J, et al. Effectiveness of home based support for older people: systematic review and meta-analysisCommentary: when, where, and why do preventive home visits work? BMJ. 2001;323(7315):719.

16. van Haastregt JC, Diederiks JP, van Rossum E, de Witte LP, Crebolder HF. Effects of preventive home visits to elderly people living in the community: systematic review. BMJ. 2000;320(7237):754-8.

17. Aslam H, Kemp L. Home visiting in South Western Sydney: an integrative literature review, description and development of a generic model. Sydney: Centre for Health Equity Training Research and Evaluation; 2005.

18. Kendrick D, Elkan R, Hewitt M, Dewey M, Blair M, Robinson J, et al. Does home visiting improve parenting and the quality of the home environment? A systematic review and meta analysis. Arch Dis Child. 2000; 82(6):443-51.

19. Medhanyie A, Spigt M, Kifle Y, Schaay N, Sanders D, Blanco R, et al. The role of health extension workers in improving utilization of maternal health services in rural areas in Ethiopia: a cross sectional study. BMC Health Serv Res. 2012;12(1):1.

20. Billings J, Zeitel L, Lukomnik J, Carey TS, Blank AE, Newman L. Impact of socioeconomic status on hospital use in new York City. Health Aff. 1993; 12(1):162-73.

21. Dias SF, Severo M, Barros H. Determinants of health care utilization by immigrants in Portugal. BMC Health Serv Res. 2008;8(1):1.

22. Tey N-P, Lai S-I, Correlates of and barriers to the utilization of health services for delivery in South Asia and sub-Saharan Africa. Sci World J 2013;2013.

23. Son M, Armstrong B, Choi J, Yoon T. Relation of occupational class and education with mortality in Korea. J Epidemiol Community Health. 2002; 56(10):798-9.

24. Matsumura M, Gubhaju B. Women's status, household structure and the utilization of maternal health Services in Nepal: even primary-leve1 education can significantly increase the chances of a woman using maternal health care from a modem health facility. Asia-Pac Popul J. 2001; 16(1):23-44

25. Paudel D, Fitakmanaket O. Utilization of maternal health Services in Nepal. JHAS. 2010;1 (1):28-37.

26. Mohammadbeigi A, Hassanzadeh J, Eshrati B, Rezaianzadeh A. Decomposition of inequity determinants of healthcare utilization, Iran. Public Health. 2013;127(7):661-7.

27. Sharma SK, Sawangdee Y, Sirirassamee B. Access to health: women's status and utilization of maternal health services in Nepal. J Biosoc Sci. 2007;39(05): $671-92$

28. Moon RY, Cheng TL, Patel KM, Baumhaft K, Scheidt PC. Parental literacy level and understanding of medical information. Pediatrics 1998;102(2):e25-e.

29. Baker DW, Parker RM, Williams MV, Clark WS, Nurss J. The relationship of patient reading ability to self-reported health and use of health services. Am J Public Health. 1997;87(6):1027-30.

30. Bakeera SK, Wamala SP, Galea S, Peterson S, Pariyo GW. Community perceptions and factors influencing utilization of health services in Uganda. Int J Equity Health. 2009;8(1):1.

\section{Ready to submit your research? Choose BMC and benefit from:}

- fast, convenient online submission

- thorough peer review by experienced researchers in your field

- rapid publication on acceptance

- support for research data, including large and complex data types

- gold Open Access which fosters wider collaboration and increased citations

- maximum visibility for your research: over $100 \mathrm{M}$ website views per year

At BMC, research is always in progress.

Learn more biomedcentral.com/submissions 